\title{
Profile and outcome of pregnancy with congenital heart diseases: a retrospective study from a South Indian tertiary care hospital
}

\author{
Mamatha S. ${ }^{1 *}$, Hemapriya L. ${ }^{1}$, Mahesh M. ${ }^{2}$, Madhumitha M. ${ }^{3}$
}

\begin{abstract}
${ }^{1}$ Department of Obstetrics and Gynecology, ${ }^{2}$ Department of Medicine, ${ }^{3}$ MBBS Student, JSS Medical College, JSS Academy of Higher Education and Research, Deemed University, Mysore, Karnataka, India
\end{abstract}

Received: 31 January 2018

Accepted: 09 February 2018

\author{
*Correspondence: \\ Dr. Mamatha S., \\ E-mail: mamathamahesh106@gmail.com
}

Copyright: (c) the author(s), publisher and licensee Medip Academy. This is an open-access article distributed under the terms of the Creative Commons Attribution Non-Commercial License, which permits unrestricted non-commercial use, distribution, and reproduction in any medium, provided the original work is properly cited.

\section{ABSTRACT}

Background: Women with congenital heart disease who become pregnant form an important subgroup of pregnancy cardiac disorders. The additional stress of pregnancy represents a further challenge.

Methods: This was a retrospective study. Patient records between 2011 and 2015 pertaining to 77 pregnant women with congenital heart diseases were analysed.

Results: There was only one patient aged more than 35 years. The age of the others ranged from 18 to 35 years. The mean age was 24 years. There was a slight rural preponderance with $43(55.8 \%)$ from rural areas. Majority 49 $(63.5 \%)$ belonged to lower middle socioeconomic status. $71(92.2 \%)$ had NYHA functional Class I. Two patients of Class II had worsening of their status. There were no cases of Atrial Fibrillation and only 2(2.6\%) had CCF.ASD closure was the commonest procedure done24 (31.2\%). There were $6(7.8 \%)$ cases of device closure of PDA and no cases of VSD. Anemia and GDM were seen in $4(5.2 \%)$. The commonest period of gestation at delivery was 37-40 in $64(83.1 \%)$. ASD was the commonest type of lesion 42 (54.5\%). $36(46.8 \%)$ had spontaneous labour and there were 18 23.4\%)caesarians. Previous LSCS was the commonest indication for LSCS. Full term normal vaginal delivery was seen in $45(88.2 \%)$. Majority of the newborns 30 (39\%) had a birth weight in the range 2.6-3.0 kgs.

Conclusions: There is a significant burden of Heart disease with pregnancy afflicting young rural women and those from lower socioeconomic levels. Higher level of specialised care minimizes poor maternal and fetal outcomes.

Keywords: Cardiac defects, Congenital abnormalities, Gestation, Heart disorders

\section{INTRODUCTION}

Availability and usage of better surgical and medical modalities in the management of congenital heart diseases in childhood has resulted in higher survival of those afflicted children into adult hood. This in turn is reflected in increased prevalence of adults with congenital heart diseases(ACHD). ${ }^{1}$ In advanced countries like USA there are now more adults with CHD than children with $\mathrm{CHD}{ }^{2}$ The incidence of congenital heart disease in pregnancy has increased over the last 30 years which is attributed to the improving results of surgical and catheter interventions, which lead to survival of this female into the reproductive age group. ${ }^{3}$

Even in developing countries female children with congenital heart diseases can now survive into reproductive age because of improved cardiac surgery and catheter based procedures available. The number of such cardiac patients at risk is expected to grow Pregnancy entails further risks in those with ACHD. In view of the variety of conditions and abnormalities it is difficult to prognosticate accurately the maternal and fetal outcomes. $4^{4}$ 
Significant increases in cardiac output, decrease in peripheral vascular resistance, increase in blood volume and heart rate are well known changes in Pregnancy. These changes impose an additional stress on the cardiovascular system of those with congenital heart disorders. ${ }^{5}$ There is also increased risk of thromboembolic complications, dysrythmias and endocarditis. ${ }^{6}$ The modern inclination and practice of working women to conceive at a much older age also adds to the increased maternal and fetal risk. ${ }^{7,8}$

In our country a good section of the population still do not practice family planning and such women with preexisting congenital heart diseases are at great risk for cardiac and non cardiac complications. Therapeutic abortions and miscarriages are ever present risks for such mothers. ${ }^{5}$ Insofar as the risk of CHD being genetically transmitted to the foetus, the overall incidence is dictated by the nature of the defect in the mother. ${ }^{8}$

There are only a few studies in this regard from South India. Hence the present study was taken up. This study looked into the clinical profile of pregnant women with congenital heart diseases with reference to parameters such as duration of heart disease, trimester status at diagnosis, symptoms, type of lesion, comorbid conditions, obstetric score birth weight of infant and postpartum complications.

\section{METHODS}

This was a retrospective study carried out at Mysore City in the South Indian state of Karnataka. JSS Hospital is a large tertiary care teaching hospital attached to JSS Medical College, having cardiology with cathlab and a cardiothoracic surgery department. The study included 77 pregnant patients with adult congenital heart disease who were admitted to the Department of Obstetrics and Gynecology and Cardiology. These women were either following up or referred to the cardiology department of our hospital for medical treatment, catheter or surgical intervention. The study population duration was 5 years starting from 2011 January till the end of December 2016. We included all female patients with ACHD defined as those patients who diagnosed, treated, and followed up during their pediatric years. We also included de novo adults, previously undiagnosed. We excluded those with acquired heart diseases or non ACHD diagnosis.

Data was taken from the patients regarding their current or previous pregnancies Details of history, personal history, history of the present illness, past history, with especial emphasis on the gestational history, number of previous pregnancies, current pregnancy status, miscarriages, abortions, cardiac and obstetric complications. Gestational age at delivery, mode of delivery was obtained.
Details of maternal cardiac complications (heart failure (congestive cardiac failure), arrhythmias, thromboembolic complications, syncope, infective endocarditis or death) and obstertric complications (as post-partum hemorrhage, low birth weight, still birth or birth defects) were also obtained from the case records.

\section{Statistical analysis}

Categorical variables were expressed as absolute and relative frequencies (percentage) while continuous variables were presented as mean values \pm standard deviation (SD). Comparisons were made between the two groups using t-test for continuous variables and chisquare test and Pearson correlation coefficient for categorical variables. Statistical analysis was performed using SPSS (statistical package version sixteen). Difference was considered statistically significant at a $\mathrm{P}$ value $<0.05$ and highly significant at $\mathrm{P}$ value $<0.01$.

\section{RESULTS}

There were total of 77 patients. There was only one patient aged more than 35 years. The age of the others ranged from 18 to 35 years. Majority of them 37 (48.1\%) belonged to the age group 21-25 years (Table 1).

Table 1: Age distribution of patients.

\begin{tabular}{|lll|}
\hline Age & No. & Percentage \\
\hline $18-20$ & 16 & 20.8 \\
\hline $21-25$ & 37 & 48.1 \\
\hline $26-30$ & 20 & 26.0 \\
\hline $31-35$ & 3 & 3.9 \\
\hline$>35$ & 1 & 1.3 \\
\hline
\end{tabular}

Only one was a working woman whereas the rest 76 were home makers. There was a slight rural preponderance with $43(55.8 \%)$ from rural areas 51 of them belonged to the lower middle and lower socioeconomic status group (Table 2).

Table 2: Socio economic status of the patients.

\begin{tabular}{|lll|}
\hline Socio economic status & No. & Percentage \\
\hline Lower & 2 & 2.6 \\
\hline Lower middle & 49 & 63.6 \\
\hline Upper middle & 26 & 33.8 \\
\hline
\end{tabular}

Table 3: Duration of heart disease.

\begin{tabular}{|lll|}
\hline Duration of heart disease & No. & Percentage \\
\hline$<1 \mathrm{yr}$ & 15 & 19.5 \\
\hline $1-5 \mathrm{yrs}$ & 20 & 26.0 \\
\hline $6-10 \mathrm{yrs}$ & 10 & 13.0 \\
\hline $11-15 \mathrm{yrs}$ & 8 & 10.4 \\
\hline $15-20 \mathrm{yrs}$ & 8 & 10.4 \\
\hline$>20 \mathrm{yrs}$ & 16 & 20.8 \\
\hline
\end{tabular}


Duration of heart disease was more than 20 years in 16 $(20.8 \%)$ of patients reflecting the increased survivability of congenital heart disease patients in todays age (Table 3).

Table 4: Obstetric and medical comorbidity.

\begin{tabular}{|lll|}
\hline Obstetric and medical comorbidity & No. & $\%$ \\
\hline Gest HTN & 0 & \\
\hline Pre eclampsia & 2 & 2.6 \\
\hline Hypothyroid & 0 & \\
Anaemia & 4 & 5.2 \\
\hline GDM & 4 & 5.2 \\
\hline Threatened preterm labour & 2 & 2.6 \\
\hline Pre termlabour & 2 & 2.6 \\
\hline
\end{tabular}

Most 10 (13\%) were diagnosed during the first trimester itself. 71 (92.2\%) had NYHA functional Class I None were in Class II and III. Two patients of Class II had worsening of their status. There were no cases of Atrial Fibrillation and only $2(2.6 \%)$ had CCF. ASD closure was the commonest procedure done 24 (31.2\%). SBE prophylaxis was given in $66(85.71 \%)$ patients. As regards obstetric and medical comorbidity anemia and GDM were seen in $4(5.2 \%)$ (Table 4$)$.

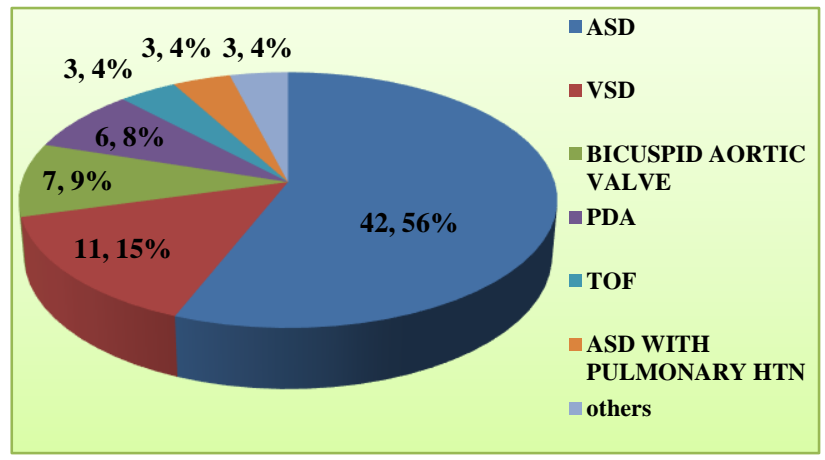

Figure 1: Types of lesions.

Gravida one $34(44.2 \%)$ was the commonest obstetric score. The commonest Period of Gestation at delivery was $37-40$ in $64(83.1 \%)$. ASD was the commonest type of lesion $42(54.5 \%)$ (Figure 1). There were $6(7.8 \%)$ cases of device closure of PDA and no cases of VSD (Table 5).

Table 5: Type of procedure.

\begin{tabular}{lll}
\hline Procedure done & No. & $\%$ \\
\hline ASD Closure & 24 & 31.2 \\
\hline VSD closure & 0 & 0.0 \\
\hline PDA device closure & 6 & 7.8 \\
\hline Both ASD and PDA closure & 1 & 1.3 \\
\hline Balloon valvuloplasty pulmonary & 4 & 5.2 \\
\hline Balloon valvuloplasty aortic & 1 & 1.3 \\
\hline Fontan's repair & 1 & 1.3 \\
\hline $\begin{array}{l}\text { Rerouting of PAPVC with pericardial } \\
\text { buffering }\end{array}$ & 2 & 2.6 \\
\hline
\end{tabular}

$36(46.8 \%)$ had spontaneous labour and there were 18 (23.4\%) caesareans (Figure 2).

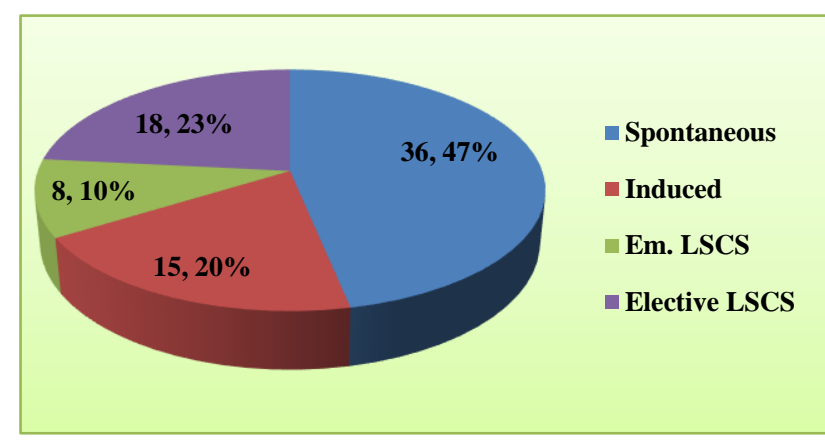

Figure 2: Type of labour.

Term pregnancy was the commonest indication for labour seen in $1414(18.2 \%)$. Previous LSCS was the commonest indication for LSCS. Spinal anesthesia was used in $25(96.2 \%)$ (Table 6).

Table 6: Indication for LSCS.

\begin{tabular}{|lll|}
\hline Indication for LSCS & No. & $\%$ \\
\hline Previous LSCS & 7 & 26.9 \\
\hline Previous sling surgery & 2 & 7.7 \\
\hline Malpresentation & 6 & 23.1 \\
\hline Contracted pelvis & 2 & 7.7 \\
\hline Failed induction & 2 & 7.7 \\
\hline Cephalo pelvic disproportion & 2 & 7.7 \\
\hline Non progress of labour & 4 & 15.4 \\
\hline PROM & 1 & 3.8 \\
\hline
\end{tabular}

Full term normal vaginal delivery was seen in 45 $(88.2 \%)$. Majority of the new-borns $30(39 \%)$ had a birth weight in the range 2.6-3.0 kgs. $11(14.3 \%)$ had postpartum complications out of whom $7(9.1 \%)$ needed ICU care (Figure 3).

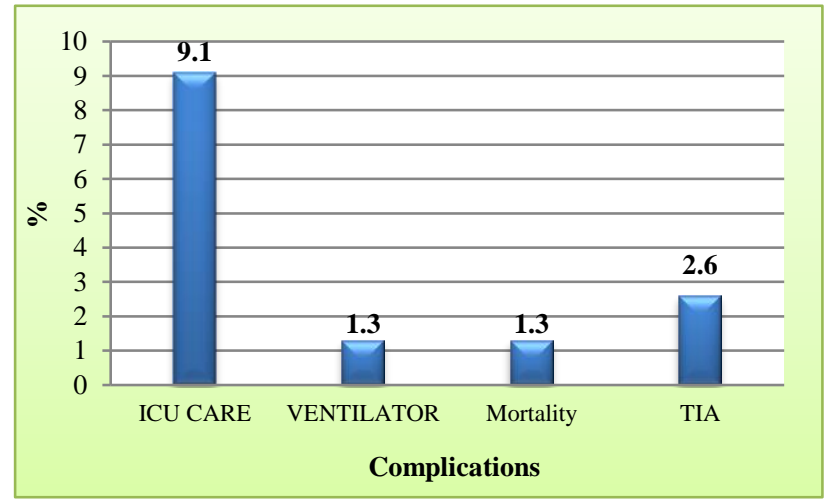

Figure 3: Post partum complications.

\section{DISCUSSION}

In this study there was one patient aged more than 35 years. The age of other remaining patients ranged from 18 years to 35 years. The largest being the 21-25 years 
group. The mean age of 23 years is relatively lower than that seen in studies from western countries. Furenas E mentioned that the mean of age in his study was 29 years and the mean age at the time of the first pregnancy was 28 years. ${ }^{10}$ This is because of our subjects being from lower socioeconomic status.

In the study by Thompson JL the common lesions encountered were as follows ASD (22.6\%), VSD, (14.5\%), LVOTO (13.8\%), right sided congenital valvular lesions $(7.5 \%)$. less common coarctation of aorta (2.9\%), TOF (2.6\%), TGA (1.5\%) Ebstein anomaly $(1.4 \%)$, TAPVR $(0.1 \%)$ and truncus arteriosus $(0.1 \%)$. The findings of present study have shown similar results. ${ }^{11}$ Thompson JL et al reported that among 655 women the incidence of cardiovascular complications was $4.1 \%$ mostly due to arrhythmia, heart failure, stroke and myocardial infarctions, hypertension. ${ }^{11}$ The results of present study are similar.

Roos-Hesselink JW reported outcomes of 872 women with congenital heart disease, $8 \%$ of which had cardiovascular decompensation or failure, while Karamlou et al found a rate of composite cardiac complications of $2.3 \%$ in women with CHD compared with $0.2 \%$ in those without. ${ }^{12,13}$ Maternal mortality was not seen in our study, however, maternal morbidity was considerable Furenas et al also reported less incidence in their paper. ${ }^{10}$ No patient in present study had therapeutic abortions. In the Zahara registry miscarriages occurred in $20 \%$ of pregnancies and in the study by Furenas it was seen in $12.6 \% .^{10,14}$

Adequate care during pregnancy, delivery, and the postpartum period requires a multidisciplinary team approach with cardiologists, obstetricians, and anaesthetists. ${ }^{15}$ The study by Hidano et al found that 128 pregnant women with CHDs had 151 uneventful pregnancy outcomes, $56 \%$ had normal vaginal delivery. ${ }^{16}$ Present results are in agreement with the results of above study. This reflects the optimal care and follow-up being given in a tertiary teaching hospital like ours.

The limitations of this study are: the data is a retrospectively collected one which leads to selection bias. The small sample is another drawback which limits analysis. Also, the study was conducted at a single centre. A large prospective multicentric study from Indian population is needed to throw more precise data regarding the issue.

\section{CONCLUSION}

There is a significant burden of Heart disease with pregnancy afflicting young rural women and with preponderance among those from lower socioeconomic levels. Operative abdominal deliveries and neonatal ICU admissions are more common in women with CHD, but these pregnancies are generally well tolerated with low mortality rates. This is in conformity with other studies from developing countries. Higher levels of general and obstetric care with appropriate Cardiological and Cardiosurgical interventions help in improving outcomes for the mother and the baby.

\section{ACKNOWLEDGMENTS}

Authors would like to thank Dr. Nagaraj Desai, Head Department of Cardiology, Dr. Ambarisha Bhandiwad, Head of Obstetrics and Gynecology, Dr. Guruswamy M. Medixal Superintendent, Mr. Shivanad Swamy In-Charge Medical Records Section JSS Hospital for their support during study.

\section{Funding: No funding sources}

Conflict of interest: None declared

Ethical approval: The study was approved by the Institutional Ethics Committee

\section{REFERENCES}

1. Drenthen W, Boersma E, Balci A, Moons P, RoosHesselink JW, Mulder BJ et al. Predictors of pregnancy in women with congenital heart disease. Eur Heart J. 2010 Jun 28;31(17):2124-32.

2. Franklin WJ, Gandhi M. Congenital heart disease in pregnancy. Cardiol Clin. 2012 Aug;30(3):383-94.

3. Alistair B, James C. New congenital heart disease review. A national review for congenital heart services for children and adults. Circulation. 2015;1:45.

4. Bhatt AB, Foster E, Kuehl K, Alpert J, Brabeck S, Crumb S, et al. Congenital heart disease with older adult. A scientific statement from the American Heart Association. Circulation. 2015;131:1884-931.

5. Curry R, Swan L, Steer PJ. Cardiac disease in pregnancy. Curr Opin Obstet Gynecol. 2009;21:50813.

6. Franklin WJ, Benton MK, Parekh DR. Cardiac disease in pregnancy. Tex Heart Inst J. 2011;38:1513.

7. Marelli AJ, Ionescu-Ittu R, Mackie AS, Guo L, Dendukuri N, Kaouache M. Lifetime prevalence of congenital heart disease in the general population from 2000 to 2010. Circulation. 2014 Aug 26;130(9):749-56.

8. Jastrow N, Meyer P, Khairy P, Mercier LA, Dore A, Marcotte F, et al. Prediction of complication in pregnant women with cardiac diseases referred to a tertiary center. Int J Cardiol. 2011;151:209-13.

9. Lu CW, Shih JC, Chen SY, Chiu HH, Wang JK, Chen CA, et al. Comparison of 3 risk estimation methods for predicting cardiac outcomes in pregnant women with congenital heart disease. Circulation. 2015;79:1609-17.

10. Furenas E, Eriksson P, Wennerholm UB, Dellborg M. Effect of maternal age and cardiac disease severity on outcome of pregnancy in women with congenital heart disease. Int J Cardiol. 2017;243:197203. 
11. Thompson JL, Kuklina EV, Bateman BT, Callaghan WM, James AH, et al. Medical and obstetric outcomes among pregnant women with congenital heart disease. Obstet Gynecol. 2015;126:346-54.

12. Roos-Hesselink JW, Huisman CM, Zwart JJ, Duvekot JJ, Roosmalen JV. Incidence and predictors of maternal cardiovascular mortality and severe morbidity in the Netherlands: A Prospective Cohort Study. Plos one. 2013;8:e56494.

13. Karamlou T, Diggs BS, Mc Crindle BW, Welke KF. A growing problem: Maternal death and peripartum complications are higher in women with grown-up congenital heart disease. Ann Thorac Surg. 2011;92:2193-9.

14. Rao S, Ginns JN. Adult congenital heart disease and pregnancy. Semin Perinatol. 2014;38:260-72.
15. Uebing A, Steer PJ, Yentis SM, Gatzoulis MA. Pregnancy and congenital heart disease. BMJ. 2006 Feb 16;332(7538):401-6.

16. Hidano G, Uezono S, Terui K. A retrospective study of adverse maternal and neonatal outcomes for parturients with congenital heart disease. Int J Obstet Anesthiol. 2011;20:229-35.

Cite this article as: Mamatha S, Hemapriya L, Mahesh M, Madhumitha M. Profile and outcome of pregnancy with congenital heart diseases: a retrospective study from a South Indian tertiary care hospital. Int J Reprod Contracept Obstet Gynecol 2018;7:883-7. 